\title{
A phase II trial with gemcitabine and paclitaxel for the treatment of refractory and relapsed multiple myeloma patients
}

\author{
YAIR GAZITT $^{1}$, PAUL SHAUGHNESSY ${ }^{2}$ and MACE L. ROTHENBERG ${ }^{3}$ \\ ${ }^{1}$ University of Texas Health Science Center; ${ }^{2}$ Texas Transplant Institute, San Antonio, TX; \\ ${ }^{3}$ Vandebilt University Medical Center, Nashville, TN, USA \\ Received April 10, 2006; Accepted May 19, 2006
}

\begin{abstract}
Multiple myeloma (MM) is an incurable disease with a 10 -year survival of $<20 \%$. We have previously shown that the combination of gemcitabine and paclitaxel acts synergistically to induce apoptosis of myeloma cells in vitro. Based on these preclinical studies and phase I-II clinical trials in patients with solid tumors, we initiated a phase II clinical trial of paclitaxel $150 \mathrm{mg} / \mathrm{m}^{2} \mathrm{IV}$ over $3 \mathrm{~h}$ followed by gemcitabine $3000 \mathrm{mg} / \mathrm{m}^{2}$ IV over 30-60 min in patients with relapsed or refractory MM. This regimen was administered every two weeks for a total of six cycles. Twelve patients enrolled, 3 discontinued treatment after 1 or 2 cycles because of severe neutropenia. As a result the protocol was modified to reduce the starting dose of gemcitabine to $2,000 \mathrm{mg} / \mathrm{m}^{2}$. This resulted in tolerable hematological and mild nonhematological toxicities in the rest of the patients. One patient died before the onset of treatment. Of the 8 remaining patients treated with a reduced dose of gemcitabine, 1 achieved a durable $\mathrm{CR}, 3$ had $\mathrm{PR}, 1$ had minor response (MR), 1 had stable disease and 2 had progressive disease. The CR patient had a $98 \%$ reduction in the M-protein, 32 microglobulin and plasma cells. His CR continued for more than 6 months. The $3 \mathrm{PR}$ patients had a $>50 \%$ reduction in the $\mathrm{M}$-protein and $>40 \%$ reduction in 32 -microglobulin. Bone marrow plasma cells were reduced by $>50 \%$ in these patients. Treatment with the combination of paclitaxel and gemcitabine is an active and well-tolerated regimen in patients with relapsed or refractory multiple myeloma.
\end{abstract}

\section{Introduction}

Multiple myeloma is an incurable, clonal, B-cell malignancy (1-3). Little progress has been made during the last 25 years in the overall survival of patients with MM using standard

Correspondence to: Dr Yair Gazitt, Department of Medicine/ Hematology, University of Texas Health Science Center, 7703 Floyd Curl Drive, San Antonio, TX 78284, USA

E-mail: email:gazitt@uthscsa.edu

Key words: gemcitabine, paclitaxel, phase II, multiple myeloma chemotherapy (4). High dose chemotherapy with autologous peripheral blood stem cell (PBSC) rescue has resulted in an initial CR rate of $>50 \%$ but 10 -year survival remains $<20 \%$ (5-9). Relapse of MM patients following transplantation is attributed to residual myeloma cells in the host following the myeloablative treatment, and/or to the emergence of a resistant clone of myeloma cells present in the host as was shown by us and by others $(10,11)$.

Newer therapies have been developed in the past 5 years to treat relapse and refractory MM patients with some promising results. These therapies include thalidomide (12-14), lenalidomide (CC-5013) (15) and bortezomib (16).

Gemcitabine (2',2'-difluorodeoxycytidine; $\mathrm{dFdC})$ is a pyrimidine analog that possesses a broad range of antitumor activity against solid tumors and leukemias in vitro and in vivo $(17,18)$. The triphosphate form of the drug competes with dCTP for incorporation into DNA resulting in DNA chain termination (19). Gemcitabine cytotoxicity is proportional to the intracellular concentration of $\mathrm{dFdCTP}$ and its incorporation into DNA. The diphosphate of gemcitabine exerts a time and concentration dependent inhibition of ribonucleotide reductase, thereby reducing intracellular $\mathrm{dCTP}$ and enhancing the incorporation of dFdCTP into DNA $(20,21)$.

In phase I clinical trials, gemcitabine was evaluated in a variety of schedules: daily x 5 every 21 days (22), twice weekly x 3 every 28 days (as a $30 \mathrm{~min}$ infusion and as a $5 \mathrm{~min}$ bolus) (23), once weekly x 3 every 28 days (24), once every 2 weeks (25), and prolonged intravenous infusion weekly $\mathrm{x} 3$ every 4 weeks (26). Objective responses were observed in patients with various solid tumors in the phase I trials. Subsequent evaluation of gemcitabine in phase II and III clinical trials revealed significant clinical activity in a variety of tumors, including pancreatic, bladder, breast, ovarian, and non-small cell lung cancer.

Paclitaxel is an antimitotic drug that promotes microtubular aggregation and affects cellular functions such as cell transport and motility with little effect on DNA, RNA, or protein synthesis $(27,28)$. Paclitaxel has demonstrated a broad range of activity against a number of solid tumors and is widely used in the treatment of non-small cell lung, epithelial ovarian, urothelial transitional cell, and head and neck cancers (29-33). There has been little clinical evaluation of paclitaxel in multiple myeloma. One study utilizing relatively low doses of paclitaxel $\left(125 \mathrm{mg} / \mathrm{m}^{2}\right.$ over $24 \mathrm{~h}$ or $135 \mathrm{mg} / \mathrm{m}^{2}$ over $3 \mathrm{~h}$ ) reported responses in $5 / 33$ patients with 
newly diagnosed multiple myeloma (response rate $=15 \%$; 95\% CI $=5-32 \%)(33)$.

A sound theoretical rationale exists for evaluating the combination of gemcitabine and paclitaxel. i) Gemcitabine and paclitaxel have different cellular targets (DNA synthesis and microtubules, respectively) and act at different phases of the cell cycle ( $S$ phase for gemcitabine and mitosis for paclitaxel). ii) Their different mechanisms of action are likely to induce distinct, non-overlapping patterns of resistance. A challenging aspect to the development of a gemcitabine/ paclitaxel combination is the differing drug administration schedules used for each of these agents: A 4-week treatment cycle for gemcitabine and a 3-week treatment cycle for paclitaxel. Adoption of one schedule would require a compromise of the other. A 4-week treatment cycle would preserve the gemcitabine treatment schedule, but would reduce the paclitaxel dosing frequency by $33 \%$ (from q 3 weeks to q 4 weeks). This schedule could also lead to difficulties in the administration of the Day 15 gemcitabine due to the timing of the paclitaxel-induced granulocyte nadir. A 3-week treatment schedule would preserve the paclitaxel dosing interval but would require omission of the Day 15 gemcitabine dose in exchange for a week of rest. This would reduce the number of gemcitabine treatments from 3 per cycle to 2 per cycle and could potentially reduce the effectiveness of this component of therapy. Fortunately, both gemcitabine and paclitaxel have been tested using a biweekly schedule. In a phase I study conducted in Italy, the MTD of gemcitabine was $4,560 \mathrm{mg} / \mathrm{m}^{2}(25)$. This represents the highest MTDs for gemcitabine achieved in phase I using any schedule. Paclitaxel, infused over $3 \mathrm{~h}$, has been administered on a q 2-week schedule in doses up to 90 to $100 \mathrm{mg} / \mathrm{m}^{2}$ (with cisplatin) (35). This was achieved without the routine use of hematopoietic growth factors. We performed a phase I trial of the combination of gemcitabine and paclitaxel in 42 patients with refractory solid tumors (36). Paclitaxel doses of $75-175 \mathrm{mg} / \mathrm{m}^{2} \mathrm{IV}$ over $3 \mathrm{~h}$ were followed by gemcitabine $1,500-3,500 \mathrm{mg} / \mathrm{m}^{2} \mathrm{IV}$ over $30 \mathrm{~min}$ administered once every two weeks. Dose-limiting toxicities included grade 3 transaminase elevation and grade 4 neutropenia lasting for more than 5 days. The recommended phase II dose was paclitaxel $150 \mathrm{mg} / \mathrm{m}^{2}$ and gemcitabine $3,000 \mathrm{mg} / \mathrm{m}^{2}$ administered once every two weeks. None of the 6 patients treated at this level experienced dose-limiting toxicity.

We have previously shown that gemcitabine and paclitaxel induce effective cytotoxicity, in vitro against various myeloma cell lines as single agents, and act synergistically at very low doses (34). The time and dose titration of gemcitabine and paclitaxel revealed an IC50 of $5 \mu \mathrm{M}$ for gemcitabine in myeloma cell lines expressing either high, or low levels of bcl-2. Paclitaxel, on the other hand was found more effective in cells with low levels of bcl-2 compared to the same cells expressing high levels of bcl-2, with IC50 of $<0.1 \mu \mathrm{M}$ and $>1 \mu \mathrm{M}$, respectively. The combination of the two drugs, at 5 -10-fold lower doses, was effective in killing $>95 \%$ of myeloma cells following $24 \mathrm{~h}$ of treatment, regardless of the level of expression of bcl-2 (34). Pharmacokinetic studies of paclitaxel administered to cancer patients at $135 \mathrm{mg} / \mathrm{m}^{2}(3 \mathrm{~h}$ infusion), revealed a peak plasma concentration of $2.5 \mu \mathrm{M}$ (29). Pharmacokinetic studies of gemcitabine, at $3,000 \mathrm{mg} / \mathrm{m}^{2}$
(1.5 $\mathrm{h}$ infusion) revealed a peak plasma concentration of $100 \mu \mathrm{M}$ (37). These concentrations are $>50$-fold higher than the IC50 we observed in vitro for the combination gemcitabine and paclitaxel in myeloma cell lines (34). Based on this broad spectrum of clinical activity and the encouraging activity of gemcitabine against resistant myeloma cells in vitro, we felt that further evaluation of this drug in patients with relapsed and refractory myeloma is warranted. Hence, we designed a phase II trial of gemcitabine and paclitaxel in patients with relapsed and refractory multiple myeloma. The goals of this study were: To determine the objective response-rate to the combination of gemcitabine and paclitaxel for patients with MM who were resistant to or had relapsed after conventional therapy, and to assess the toxicity and tolerability of the regimen in this group of patients.

\section{Patients and methods}

Patients were enrolled from Audie L. Murphy Veterans Administration Medical Center, University Hospital and Wilford Hall Medical Center at San Antonio, TX; Northwestern University Medical Center, Chicago, IL and Vanderbilt Medical Center, Nashville, TN. Informed consent was obtained by the participating investigators in the different institutions. The protocol was approved by the local IRB of all the institutions involved in this study. Informed consent was obtained from all patients before entry into the study. Patients could have received prior high dose chemotherapy and stem cell transplantation and relapsed after multiple lines of chemotherapy. Other inclusion criteria were Zubrod Performance Score of $0-2$, serum creatinine of $<2.5 \mathrm{mg} / \mathrm{dl}$; bilirubin $\leq 2.5 \mathrm{mg} / \mathrm{dl}$; transaminases $\leq 2 \mathrm{x}$ institutional upper limit of normal levels with no evidence of active bacterial infection; $A N C \geq 1500 / \mu 1$ and platelets $\geq 100,000 / \mu 1$. While on trial, patients were allowed to receive concurrent bisphosphonate treatment for bone lesions and hematopoietic growth factor (G-CSF) support according to ASCO guidelines. No prophylactic growth factor support was allowed.

Prior to the initiation of therapy, patients underwent baseline evaluation which included CBC, serum chemistries, SPEP, quantitative immunoglobulin, B2-microglobulin and M-protein. Bone marrow aspirates were collected for routine histopathology. Patients underwent a bone survey, and $24 \mathrm{~h}$ urine collection for assessment of Bence-Jones proteinuria. Any lytic lesions not previously treated within 3 months of entering the study by radiotherapy were noted as index lesions, but were not used to assess response. Patients also had a coagulation profile (PTT/PT), chest X-ray, EKG, routine urine analysis and a pregnancy test performed, if applicable. In order to prevent severe hypersensitivity reactions, all patients were premedicated prior to receiving paclitaxel with dexamethasone $20 \mathrm{mg}$ po 12 and $6 \mathrm{~h}$ prior to paclitaxel, diphenhydramine $50 \mathrm{mg}$ IV and cimetidine $300 \mathrm{mg}$ po 30 to 60 min prior to paclitaxel.

All patients were placed on a Dynamap monitor during paclitaxel infusion and their blood pressure and pulse rate were checked every $15 \mathrm{~min}$. All patients began treatment by receiving an infusion of $150 \mathrm{mg} / \mathrm{m}^{2}$ of paclitaxel (MeadJohnson, Princeton, NJ) through a peripheral IV access over a period of $3 \mathrm{~h}$. This was followed by an IV infusion of 
Table I. Dose modification due to hematological toxicities.

\begin{tabular}{|c|c|c|c|}
\hline $\begin{array}{l}\text { ANC } \\
\left(\times 10^{9} / 1\right)\end{array}$ & $\begin{array}{c}\text { Platelets } \\
\left(\mathrm{x} 10^{9} / 1\right)\end{array}$ & Paclitaxel & Gemcitabine \\
\hline$\geq 1.5$ & and $\geq 75$ & Full dose & Full dose ${ }^{a}$ \\
\hline $1.0-1.49$ & $50-74.9$ & -1 dose & Full dose \\
\hline $0-0.99$ & $0-49.9$ & -1 dose & -1 dose \\
\hline
\end{tabular}

${ }^{\text {aA }}$ A dose level reduction was $500 \mathrm{mg} / \mathrm{m}^{2}$ for gemcitabine and $50 \mathrm{mg} / \mathrm{m}^{2}$ for paclitaxel.

gemcitabine (Gemzar; LY 188011, 2',2'-difluorodeoxycytidine, Eli Lilly), $3000 \mathrm{mg} / \mathrm{m}^{2}$ over $30-60 \mathrm{~min}$. This treatment was repeated every two weeks. The planned course of therapy was 6 cycles. Actual body weight was used to determine BSA throughout this study. Due to the hematological toxicities associated with the high dose of gemcitabine used in the first 4 patients enrolled, the dose of gemcitabine was subsequently reduced to $2000 \mathrm{mg} / \mathrm{m}^{2}$ (see below).

Dose adjustment was based on the complete blood count and differential blood count obtained in preparation for the day of scheduled therapy. A new cycle of treatment was begun only when granulocytes count was $>1.5 \times 10^{9} / 1$ and platelets $>75 \times 10^{9} / 1$. Treatment was delayed for up to 2 weeks to allow sufficient time for recovery. Upon recovery, the patient was retreated using the guidelines outlined in Tables I and II. In cases where the cut-off for granulocytes or platelets was not met after a two-week delay, the patient was removed from the study and considered to have DLT. G-CSF at $5 \mu \mathrm{g} / \mathrm{kg}$ was administered when neutrophils were $<0.5 \times 10^{9} / 1$ for at least 5 days or in cases of neutropenic fever. Blood and platelet support was given as needed. Packed RBCs were given as needed to keep $\mathrm{Hgb}>8 \mathrm{~g} / \mathrm{dl}$. For the platelets, either single or multiple apheresis collections were given to maintain a platelet count of $>10,000$ if patient was clinically bleeding.

At baseline and after each cycle, blood samples were tested for $\mathrm{CBC}$ and differential count; Serum Protein Electrophoresis (SPEP, Albumin, Alpha-1 Fraction, Alpha-2 Fraction, Beta Fraction, Gamma Fraction); and serum chemistries. The Mprotein was quantitated by electrophoresis and immunofixation methods in urine and serum and B2-microglobulin was quantitated in the serum. The plasma cell content in bone marrow was also determined every other cycle, when possible. In addition, EKG; chest X-ray and bone survey were performed at baseline and after completion of the study (3 months).

This phase II study was designed to determine the efficacy of gemcitabine and paclitaxel in patients with relapsed or refractory MM. The study design was based on the Fleming two-stage design (38). In stage I, 15 patients are treated. If no response is seen in the first 15 patients, then one can rule out $\mathrm{a} \geq 20 \%$ response-rate and stop the trial. If 3 or more responses are obtained in the first group of 15 patients, then the trial is stopped and the drug is accepted. However, if 1-2 responses are obtained in the first group of 15 patients, an additional 20 patients are entered. If 1-3 responses are obtained among the 35 patients, then the drug is accepted if the response rate is $\geq 11.4 \%$ (4/35 patients), and the drug is rejected if the response-rate is $\leq 8.6 \%$ among the 35 patients (3/35 patients). Of the intended first phase of 15 patients only 12 patients were enrolled in this study because of slow accrual due to competitive new chemotherapy regimes for refractory MM patients, such as thalidomide and bortezomib.

Objective response rate was determined according to Southwest Oncology Group criteria: Sustained decrease in

Table II. Dose modification due to non-hematological toxicities.

\begin{tabular}{lclc}
\hline Toxicity & Toxicity level & Paclitaxel & Gemcitabine \\
\hline Bilirubin & $0-2$ & aFull dose & aFull dose \\
& 3 & -2 dose levels & -1 dose level \\
& 4 & -2 dose levels & -2 dose levels \\
Transaminases & $0-1$ & Full dose & Full dose \\
& 2 & Full dose & -1 dose level \\
& $3-4$ & Full dose & -2 dose levels \\
Myalgias or peripheral neuropathy & $0-2$ & Full dose & Full dose \\
& 3 & -1 dose level & Full dose \\
Skin rash & 4 & -2 dose levels & Full dose \\
& $0-2$ & Full dose & Full dose \\
Other toxicities except nausea/vomiting & 3 & Full dose & -1 dose level \\
& 4 & -1 dose level & -2 dose levels \\
& $0-3$ & Full dose & Full dose \\
\end{tabular}

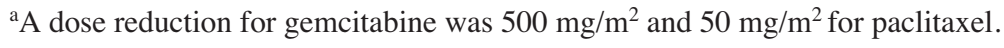


Table III. Patient characteristics.

\begin{tabular}{|c|c|c|c|c|c|c|}
\hline $\begin{array}{l}\text { Patient no. } \\
\text { and Ig }\end{array}$ & $\begin{array}{l}\text { Age/ } \\
\text { Sex }\end{array}$ & $\begin{array}{l}\text { Disease duration } \\
\text { and status }\end{array}$ & Prior therapy & $\begin{array}{l}\text { les of } \\
\text { tment }\end{array}$ & ff a Response and outcome & Comments \\
\hline $1 / \mathrm{kLC}$ & $76 / \mathrm{F}$ & $5 y / P D$ & Mel+P (x2); INF; VAD & 2 & Pan cytopenia; off protocol & $3 \mathrm{~g} / \mathrm{m}^{2} \mathrm{GEM}$ \\
\hline 2/IgG/1 & $76 / \mathrm{M}$ & 5y/progressive & Relapse post ASCT (TBI+Mel) & 0 & $\begin{array}{l}\text { Died before treatment } \\
\text { of liver disease }\end{array}$ & No treatment \\
\hline $3 / \mathrm{IgG} / \mathrm{k}$ & $54 / \mathrm{M}$ & $\begin{array}{l}\text { 3y/Relapsed post } \\
\text { Tx }\end{array}$ & VAD (x3); ASCT (TBI+Mel) & 1 & Pan cytopenia; off protocol & $3 \mathrm{~g} / \mathrm{m}^{2} \mathrm{GEM}$ \\
\hline $4 / \mathrm{kLC}$ & $66 / \mathrm{F}$ & $\begin{array}{l}\text { 4y/ Relapse post } \\
\text { Tx }\end{array}$ & VAD (x2); Mel; ASCT (Mel) & 1 & $\begin{array}{l}\text { Pan cytopenia; refused to } \\
\text { continue treatment }\end{array}$ & $3 \mathrm{~g} / \mathrm{m}^{2} \mathrm{GEM}$ \\
\hline $5 / \mathrm{IgG} / \mathrm{k}$ & $53 / \mathrm{M}$ & $2 y /$ refractory & $\begin{array}{l}\text { Multiple cycles of VAD; ASCT } \\
\text { (Mel+TBI); Thal }\end{array}$ & 4 & $\begin{array}{l}\text { Progressive disease; } \\
\text { off protocol }\end{array}$ & $2 \mathrm{~g} / \mathrm{m}^{2} \mathrm{GEM}$ \\
\hline 6/IgG/k & $63 / \mathrm{M}$ & $\begin{array}{l}\text { 8y/Relapse post } \\
\mathrm{Tx}\end{array}$ & $\begin{array}{l}\text { VAD; INF; Mitoxantrone; ASCT } \\
\text { (TBI+Mel) }\end{array}$ & 6 & MR, continued on thalidomide & $2 \mathrm{~g} / \mathrm{m}^{2} \mathrm{GEM}$ \\
\hline $7 / \mathrm{IgG} / \mathrm{k}$ & $61 / \mathrm{M}$ & hRefractory & $\begin{array}{l}\text { Multiple cycles of VAD; Mel+P; } \\
\text { INF; Mel }\end{array}$ & 6 & Achieved PR, relapsed & $2 \mathrm{~g} / \mathrm{m}^{2} \mathrm{GEM}$ \\
\hline $8 / \mathrm{IgG} / \mathrm{k}$ & $59 / \mathrm{M}$ & $\begin{array}{l}\text { 3y/Relapse post } \\
\mathrm{Tx}\end{array}$ & $\begin{array}{l}\text { Multiple Chemotherapy; XRT; } \\
\text { ASCT (TBI+Mel) }\end{array}$ & 6 & $\begin{array}{l}\text { Achieved PR; went } \\
\text { on thalidomide }\end{array}$ & $2 \mathrm{~g} / \mathrm{m}^{2} \mathrm{GEM}$ \\
\hline 9/IgG/k & $74 \mathrm{M}$ & $\begin{array}{l}\text { 4y/Smouldering } \\
\mathrm{MM}\end{array}$ & Multiple XRT; Mel+P; INF & 6 & Achieved CR & $2 \mathrm{~g} / \mathrm{m}^{2} \mathrm{GEM}$ \\
\hline $10 / \mathrm{IgG} / \mathrm{k}$ & $56 / \mathrm{M}$ & $\begin{array}{l}\text { 3y/Relapse post } \\
\mathrm{Tx}\end{array}$ & $\begin{array}{l}\text { Multiple XRT; VAD; ASCT } \\
\text { (TBI+Mel) }\end{array}$ & 6 & Achieved PR & $2 \mathrm{~g} / \mathrm{m}^{2} \mathrm{GEM}$ \\
\hline $11 / \mathrm{IgG} / \mathrm{k}$ & $66 / \mathrm{F}$ & $\begin{array}{l}\text { 5y/Relapse post } \\
\mathrm{Tx}\end{array}$ & Multiple XRT; High DEX & 6 & Remained in SD & $2 \mathrm{~g} / \mathrm{m}^{2} \mathrm{GEM}$ \\
\hline 12/1/LC & $58 / \mathrm{M}$ & 1y/refractory & Mel+P; high DEX; XRT & 6 & Died of PD & $2 \mathrm{~g} / \mathrm{m}^{2} \mathrm{GEM}$ \\
\hline
\end{tabular}

aResponse by SWOG Criteria; Mel, melphalan; XRT, radiation; Thal, thalidomide; INF, interferon; P, prednisone; DEX, dexamethasone; $\mathrm{VAD}$, vincristine/adriamycin/dexamethasone; ASCT, autologous stem cell transplantation; MR, minimal response; PR, partial response; CR, complete clinical response; SD, stable disease; GEM, gemcitabine; Tx, transplant; PD, progressive disease.

serum M-protein to $\leq 25 \%$ of the pretreatment value and a sustained decrease in the 24 -h urine M-protein to $\leq 10 \%$ of pretreatment value with a $\geq 50 \%$ decrease in bone marrow plasma cells.

\section{Results}

Twelve relapsed or refractory MM patients were enrolled into the study. The median age was 61 (53-76) years and 6 patients had relapsed after autologous stem cell transplantation. Others were refractory MM patients following multiple regimens of conventional chemotherapy with or without radiotherapy (Table III).

Response to treatment. Of the 12 patients enrolled in this trial, 1 patient died before the onset of treatment and 3 were taken off protocol because of sustained grade 4 neutropenia following the first or second cycle of treatment. The protocol was amended and the dose of gemcitabine was reduced from $3,000 \mathrm{mg} / \mathrm{m}^{2}$ to $2,000 \mathrm{mg} / \mathrm{m}^{2}$ in the subsequent 8 patients. This resulted in much more tolerable myelosuppression. Of the 8 remaining patients, 1 patient received only 4 cycles of treatment and was discontinued because of disease progression and grade 4 neutropenia, despite filgrastim support and dose reduction of gemcitabine and paclitaxel, according to the dose reduction schema (Table I). All the remaining 7 patients completed 6 cycles of treatment with 1 patient achieving a durable CR, 3 achieving PR, 1 achieving MR, 1 with SD and 1 with PD who experienced grade 4 neutropenia and died of progressive disease shortly after completing the treatment. The results are summarized in Table IV. The CR patient (no. 9) had a steady decrease in the serum M-protein during the course of treatment reaching $2 \%$ of the initial level of $1,140 \mathrm{mg} / \mathrm{dl}$ after the 6 th cycle of therapy. His B2-microglobulin levels decreased during the course of treatment from $2.5 \mathrm{mg} / 1$ to $0.1 \mathrm{mg} / \mathrm{l}$ after the 6th cycle of treatment. Percent bone marrow plasma cells (PC) declined from $39 \%$ to $1 \%$ (Table IV). This patient continued treatment off protocol, at his request, for another 6 cycles and remained in CR for the duration of treatment with all 3 myeloma indicators approaching undetectable values (Fig. 1). The levels of $\mathrm{Ca}^{++}$ remained practically the same for the duration of the treatment starting at $9.1 \mathrm{mg} / \mathrm{dl}$ and ending at $8.7 \mathrm{mg} / \mathrm{dl}$ (Fig. 1). His WBC fluctuated between 5,500 and 3,000 cells $/ \mu 1$ with nadirs of 1,000 and 1,500 cells $/ \mu 1$ after the 1 st and 6 th cycles on protocol and with sustained WBC of 1,900 to 4,800 cells/ $\mu 1$ in the next 6 cycles off protocol (Fig. 2). The patient's hemoglobin ranged between $12.7 \mathrm{~g} / \mathrm{dl}$ to $11.6 \mathrm{~g} / \mathrm{dl}$ at completion of protocol with only 1 nadir of $7.8 \mathrm{~g} / \mathrm{dl}$ where the patient received RBCs support. The patient completed 
Table IV. Follow-up of Gem-Tax protocol patients for myeloma markers.

\begin{tabular}{|c|c|c|c|c|c|c|c|c|c|c|c|c|}
\hline \multirow[t]{2}{*}{ aPt } & \multicolumn{4}{|c|}{ ß2-microglobulin/cycle of treatment } & \multicolumn{4}{|c|}{ M-protein/cycle of treatment } & \multicolumn{4}{|c|}{$\%$ Plasma cells/cycle of treatment } \\
\hline & 0 & II & IV & VI & 0 & II & IV & VI & 0 & II & IV & VI \\
\hline 6 & 5.2 & ND & $2.4(75)$ & ) & 5,170 & ND & $3,906(75)$ & $3,674(71)$ & 49 & ND & $39(79)$ & $36(73)$ \\
\hline 7 & 2.7 & $0.5(81)$ & & $1.7(63)$ & 760 & $170(22)$ & $150(20)$ & $120(16)$ & 35 & $15(43)$ & $8(23)$ & $12(34)$ \\
\hline 8 & 3.3 & $1.1(33)$ & 1.9 & $1.6(48)$ & 500 & ND & 162 & $125(25)$ & 23 & ND & $12(52)$ & $9(39)$ \\
\hline 9 & 2.5 & $2(80)$ & $1.8(84)$ & $0.1(4)$ & 1,140 & 450 & $290(25)$ & $26(2)$ & 40 & 19 (47) & $11(27)$ & $1(2)$ \\
\hline 10 & 3.5 & $3.6(103)$ & $3.5(97)$ & $2.4(68)$ & 1,420 & $1,010(71)$ & $830(58)$ & $690(48)$ & 42 & $40(95)$ & $36(85)$ & $20(49)$ \\
\hline 11 & 4.6 & $3.5(76)$ & $3.0(65)$ & $3.7(80)$ & 7,100 & $6,400(90)$ & $6,100(89)$ & $5,700(80)$ & 70 & $61(87)$ & $30(83)$ & $37(52)$ \\
\hline 12 & 6.6 & $11.1(167)$ & $6.4(97)$ & ND & 4,130 & $4,073(98)$ & $4,560(110)$ & $5,990(145)$ & ) 54 & $46(85)$ & ND & $50(92)$ \\
\hline
\end{tabular}

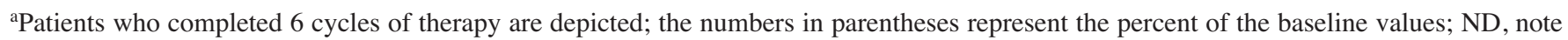
done.

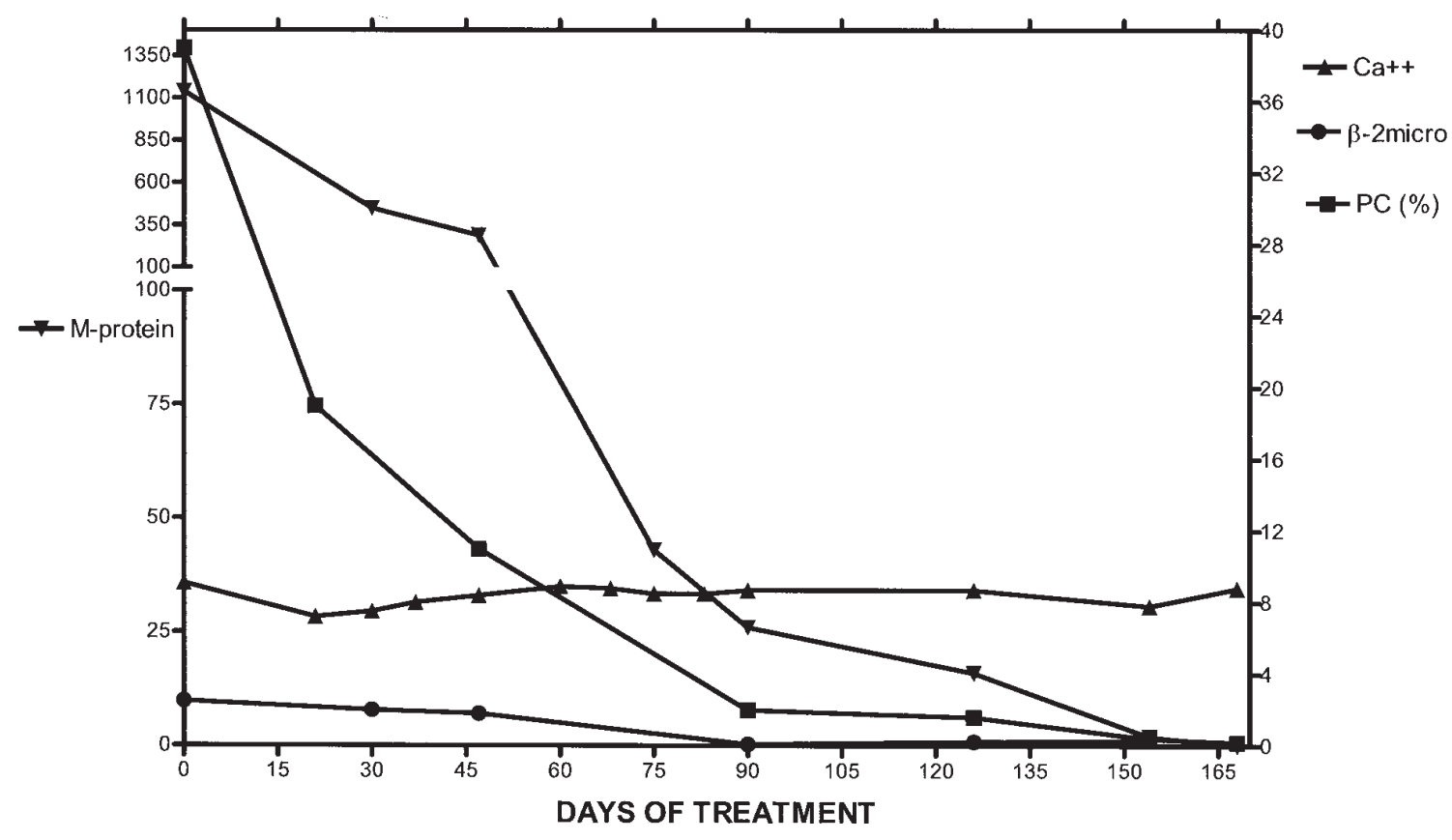

Figure 1. Decrease in the M-protein, ß2-microglobulin and bone marrow plasma cells following Gem-Tax treatment of patient no. 9 . Patient no. 9 was treated for 6 cycles on protocol and additional 6 cycles off protocol. PC, plasma cells (\% of total nucleated cells in bone marrow smears). The M-protein was measured in plasma by immunofixation. For experimental details see materials and methods.

additional 6 cycles off protocol with $\mathrm{Hgb}$ of $11.7 \mathrm{~g} / \mathrm{dl}$ (Fig. 2). Similarly, his platelet (plt) count was around 200,000 plts $/ \mu 1$ with only 1 nadir of $98,000 \mathrm{plts} / \mu \mathrm{l}$. AST values were within the normal range, between 25 to $22 \mathrm{IU} / 1$ for 5 cycles of therapy with only a single spike to $40 \mathrm{IU} / 1$ after the first cycle, after which his AST stabilized around 20-25 IU/1 for the next 6 cycles off protocol. ALT values followed similar pattern described for AST (Fig. 2). The patient's baseline $\mathrm{Ca}^{++}$level was $9.1 \mathrm{mg} / \mathrm{dl}$, decreased to 7.2 during treatment and increased back to $8.7 \mathrm{mg} / \mathrm{dl}$ at the end of the first 6 cycles. The patient remained at the same $\mathrm{Ca}^{++}$levels for the duration of the next 6 cycles off protocol (Fig. 1). He initially had a regression of his skull plasmacytoma for the duration of the treatment. Upon stopping the treatment the patient had a recurrence of his skull lesions and progression of his myeloma disease. He was then treated with radiotherapy to the skull for pain relief and with thalidomide for his myeloma disease. The patient did not tolerate thalidomide and the treatment was stopped and he died 1 year later from slow progression of his disease.

The 3 PR patients (nos. 7, 8 and 10) had a $45 \%$ to $84 \%$ reduction in M-spike with 2 patients achieving $>75 \%$ reduction in the M-spike with consistent decrease in B2-microglobulin of $32 \%$ to $52 \%$ of baseline values and a $63 \%$ to $51 \%$ reduction in the percent of bone marrow plasma cells (PC) compared to baseline values (Table IV). In $1 \mathrm{PR}$ patient (no. 7), the baseline serum $\mathrm{Ca}^{++}$level was 9.7, dropped to 8.2 and increased back to $9.8 \mathrm{mg} / \mathrm{dl}$ at the end of treatment. In another PR patient (no. 8) baseline $\mathrm{Ca}^{++}$level was 9.7, dropped to 8.6 and increased to 8.9 at the end of treatment. 


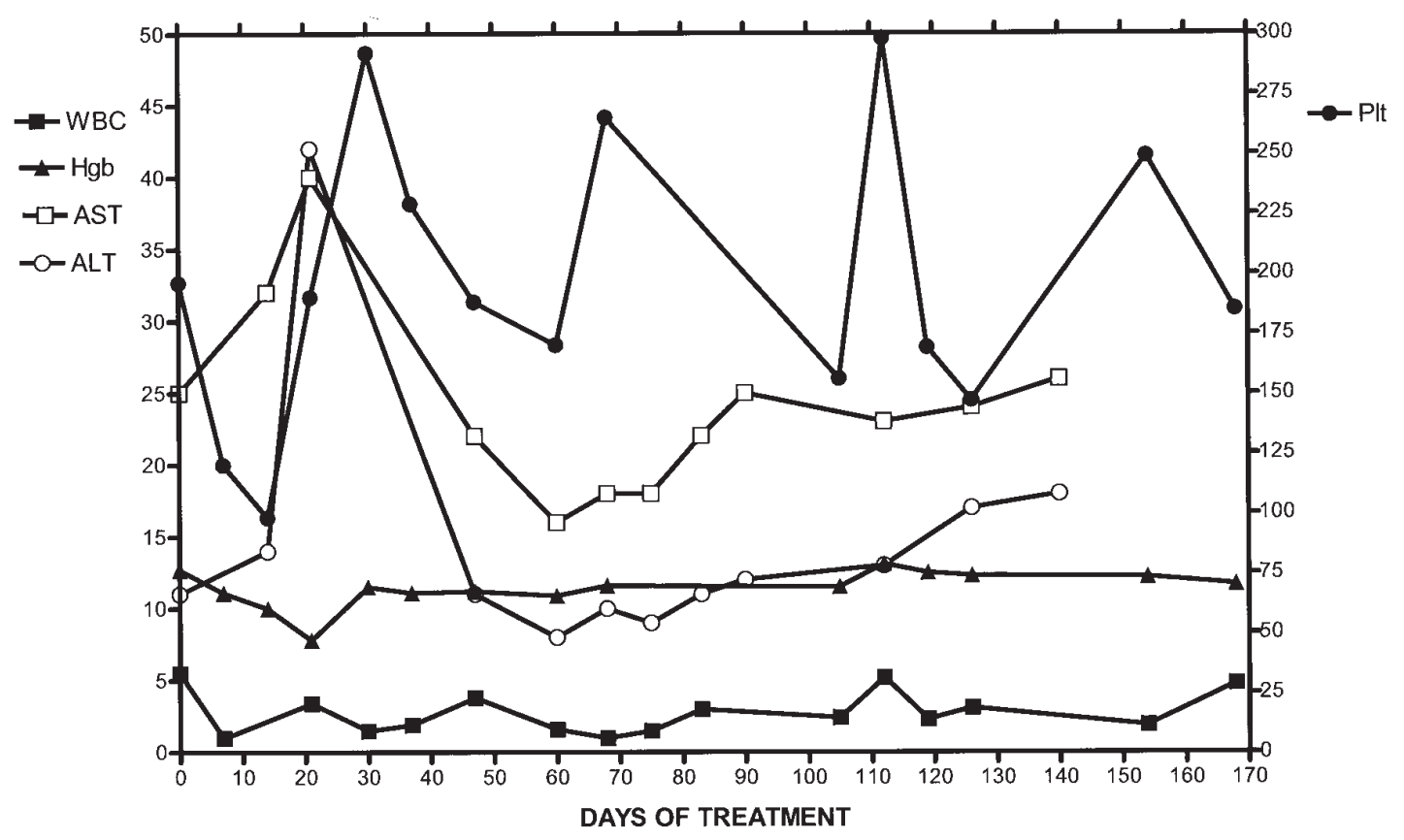

Figure 2. Fluctuations in blood counts, hemoglobin and liver enzymes following the Gem-Tax treatment of patient no. 9. He was treated for 6 cycles on protocol and additional 6 cycles off protocol. AST and ALT are liver enzymes. For experimental details see Materials and methods.

Table V. Follow-up of Gem-Tax protocol patients for non-hematological toxicities.

\begin{tabular}{|c|c|c|c|c|c|c|c|c|c|c|c|c|c|c|c|c|c|c|c|c|c|}
\hline \multirow{2}{*}{$\begin{array}{l}\text { aPt/ } \\
\text { grade }\end{array}$} & \multicolumn{2}{|c|}{ Alopecia } & \multicolumn{3}{|c|}{ Pain } & \multicolumn{3}{|c|}{ Weakness } & \multicolumn{3}{|c|}{ Mucositis } & \multicolumn{3}{|c|}{ Skin rash } & \multicolumn{4}{|c|}{ Fever } & \multicolumn{3}{|c|}{ Neuropathy } \\
\hline & I & II & I & II & III & I & II & III & I & II & III & I & II & III & I & II & III & IV & I & II & III \\
\hline 6 & 0 & 2 & 0 & 1 & 0 & 0 & 0 & 0 & 0 & 0 & 0 & 0 & 0 & 0 & 0 & 0 & 0 & 0 & 0 & 0 & 0 \\
\hline 7 & 0 & 0 & 6 & 0 & 0 & 2 & 0 & 0 & 1 & 0 & 0 & 0 & 0 & 0 & 0 & 0 & 0 & 0 & 2 & 0 & 0 \\
\hline 8 & 0 & 2 & 5 & 1 & 0 & 4 & 0 & 0 & 1 & 0 & 0 & 0 & 0 & 0 & 0 & 0 & 0 & 0 & 1 & 0 & 0 \\
\hline 9 & 0 & 0 & 0 & 0 & 0 & 0 & 0 & 0 & 0 & 0 & 0 & 0 & 0 & 0 & 0 & 0 & 0 & 0 & 1 & 0 & 0 \\
\hline 10 & 0 & 1 & 1 & 0 & 0 & 0 & 0 & 0 & 0 & 0 & 0 & 0 & 0 & 0 & 1 & 0 & 0 & 0 & 0 & 0 & 0 \\
\hline 11 & 0 & 0 & 0 & 0 & 0 & 0 & 0 & 0 & 1 & 0 & 0 & 0 & 0 & 0 & 1 & 0 & 0 & 0 & 0 & 0 & 0 \\
\hline 12 & 0 & 2 & 0 & 2 & & 0 & 0 & 1 & 0 & 0 & 0 & 0 & 0 & 0 & 0 & 0 & 0 & 1 & 0 & 1 & 0 \\
\hline
\end{tabular}

${ }^{a}$ Pt, patients. Only patients who completed 6 cycles of therapy were included. Toxicity was graded by SWOG criteria. The numbers represent cycles of observed toxicities. No grade IV toxicities were observed for pain, weakness, mucositis, skin rash and neuropathy.

The 3rd PR patient (no. 10) had $\mathrm{Ca}^{++}$baseline of 12.1, which dropped to 9.8 and bounced back to $10.8 \mathrm{mg} / \mathrm{dl}$. The patient with MR (no. 6) had $>25 \%$ consistent reduction in the 3 myeloma indicators including a reduction in skull plasmacytoma. His baseline $\mathrm{Ca}^{++}$was 11.6 , then dropped to 9.1 and increased to 10.7 at the end of treatment. All patients eventually progressed and died 1-2 years after treatment on this protocol.

Hematological toxicities. Following the dose reduction of gemcitabine, we generally observed transient and manageable hematological toxicities. Of the 8 patients treated with $2 \mathrm{~g} / \mathrm{m}^{2}$ of gemcitabine, 2 had grade 4 neutropenia and 1 had grade 3 neutropenia, all of which were resolved by conventional
RBCs, platelet and G-CSF support. All but 1 patient with grade 4 neutropenia failed hematological support (patient no. 5).

Non-hematological toxicities. Generally, non-hematological toxicities were minor and transient. Of the 7 patients who completed all 6 cycles of therapy, grade II alopecia was observed in 3/7 patients during 1-2 cycles. Level I pain was observed in 3 patients during 1-6 cycles of therapy. Grade I weakness was observed in 2 patients for 2-4 cycles and grade III weakness was observed in 1 patient for 1 cycle. Grade I mucositis was observed in 3 patients, for 1 cycle. Grade II fever was also rare with 2 patients experiencing grade II for 1 cycle. Grade I neuropathy was observed in 4 patients for 1-2 cycles and grade II neuropathy was observed in 1 patient for 
1 cycle of treatment. No skin rush was observed in any of the patients who completed 6 cycles of therapy. No grade IV toxicities were observed for alopecia, pain, weakness, mucositis, skin rash and neuropathy (Table V).

\section{Discussion}

Extensive preclinical studies of a possible in vitro synergy between paclitaxel and gemcitabine suggested a highly significant synergy between gemcitabine and paclitaxel and a variety of myeloma cell lines (34). Based on these in vitro results and the efficacy of this combination in a great variety of solid tumors, we launched a phase II clinical trial in refractory multiple myeloma patients. Of the 12 patients enrolled in this study, 4 heavily-pretreated multiple myeloma patients experienced objective responses, including one patient who achieved a durable CR. All objective responses were observed in the cohort of patients treated with a reduced starting dose of gemcitabine. This dose-reduction to $2 \mathrm{~g} / \mathrm{m}^{2}$ of gemcitabine resulted in tolerable and manageable hematological toxicities in the rest of the patients. Only one of the 8 patients treated at this dose could not receive the full 6 planned cycles of treatment, and this was due to disease progression, not drug toxicity. Of the intended first phase of 15 patients only 12 patients were enrolled in this study because of slow accrual due to competitive new chemotherapy regimes for refractory $\mathrm{MM}$ patients, such as thalidomide and bortezomib.

In recent years new treatment modalities have been developed to treat MM including thalidomide (19) and bortezomib (Velcade) (16). The first thalidomide study of 169 refractory MM patients resulted with $\sim 30$ responses and 1 CR. However, peripheral neuropathy was a major treatmentlimiting toxicity affecting $50 \%$ to $80 \%$ of the patients, the severity and reversibility of which were related to both dose and duration of drug administration of thalidomide. In other studies, thalidomide doses of $>400 \mathrm{mg}$ resulted in grade 3 neurotoxicity in approximately one third of patients (12-14). In another ongoing randomized study of 550 patients receiving Total Therapy with or without thalidomide, the 4year estimate of grade $\geq 3$ peripheral neuropathy has been about $16 \%$ in the thalidomide arm vs only $5 \%$ in the Total Therapy arm with no thalidomide treatment (9). In other studies, the combination of thalidomide and doxorubicin was tested resulting in manageable treatment related thromboembolic complications (42). Early trials of thalidomide and dexamethasone are ongoing (43).

CC-5013 (Revimid) is a thalidomide-related, newly discovered drug with lower neurotoxic side effects. Responses have been reported in one third of patients with advanced and refractory myeloma (44), however, unlike thalidomide, CC5013 causes myelosuppression especially when combined with other drugs sharing a similar toxicity profile (9).

Another newly developed drug for the treatment of MM is bortezomib (Velcade) which has been approved for the treatment of MM $(16,39)$. This drug is a proteosome inhibitor (40) which induced 35\% overall response in 202 relapsed and refractory MM patients (SUMMIT; CREST studies). The most common side effects of bortezomib (25-55\%) include nausea, diarrhea, fatigue, thrombocytopenia, neutropenia, peripheral neuropathy, vomiting and anorexia. The dose limiting toxicities (DLTs) include grade 3 hypo-natremia, fatigue, thrombocytopenia and neutropenia $(19,39)$. The overall response with this drug has been about $35 \%$ including $4 \% \mathrm{CR}$ and $6 \%$ near $\mathrm{CR}$ according to the criteria proposed by Blade et al (40-41). A combination of bortezomib and dexamethasone in patients who did not respond to bortezomib resulted in an additional response in 13/74 patients (39). In a recent study (APEX), Richardson et al (45) reported the results from randomized study of 669 patients with relapsed myeloma receiving either bortezomib followed by dexamethasone, or with dexamethasone alone. In a follow-up of 1 year, patients treated with bortezomib and dexamethasone had higher response rates, a longer time to progression and a longer survival than patients treated with dexamethasone $(\mathrm{CR}+\mathrm{PR}=38 \%$ vs $18 \%$, respectively) and $6 \%$ of patients receiving bortezomib plus dexamethasone achieved CR compared to $1 \%$ in the dexamethasone arm. Toxicities remained a problem with grade 3 or 4 adverse events observed in $75 \%$ of patients treated with bortezomib plus dexamethasone and in $60 \%$ of patients receiving dexamethasone alone (45).

In other studies, bortezomib synergizes with gemcitabine in vivo in a xenograft model of human bladder tumor (46). This recent observation and our results merit a phase I clinical trial of the combination of bortezomib and gemcitabine in refractory myeloma patients.

In summary, in this phase II trial of the combination of paclitaxel and gemcitabine for refractory and relapsed MM patients we observed objective responses in 30\% (4/12) of patients (3 PR and 1 durable CR by SWOG criteria). Hence, the responses in this small study are similar to the responses observed for bortezomib and thalidomide with fewer and manageable toxicities described above for thalidomide, CC5013 , bortezomib or combinations of these drugs with other drugs. Our results justify additional investigation of this drug combination in a larger number of refractory MM patients.

\section{Acknowledgements}

This study was supported by a grant from Eli Lilly. The authors would like to thank Dr Cesar Freytes and Dr Nathalie S. Callander from the University of Texas Health Science Center at San Antonio and Dr Anne Traynor from Northwestern University Medical Center, Chicago, IL, for enrolling, 1 patient each, for this study. We would also like to thank Ms. Patricia Devore for coordinating this study.

\section{References}

1. Kyle RA and Rajkumar SV: Multiple myeloma. N Engl J Med 351: 1860-1873, 2004.

2. Barlogie B, Epstein J, Selvanayagam P and Alexanian R: Plasma cell myeloma-new biological insights and advances in therapy. Blood 73: 865-879, 1989.

3. Abdou NI and Abdou NL: The monoclonal nature of lymphocytes in multiple myeloma. Ann Intern Med 83: 42-45, 1975.

4. Gregory W, Richards M and Malpas J: Combination chemotherapy versus melphalan and prednisone in the treatment of multiple myeloma: an overview of published trials. J Clin Oncol 10: 336-342, 1992 .

5. Attal M, Harousseau J-L, Stoppa A-M, et al: A prospective randomized trial of autologous bone marrow transplantation and chemotherapy in multiple myeloma. N Engl J Med 335: 91-97, 1996. 
6. Barlogie B, Hall R, Zander A, Dicke K and Alexanian R: High dose melphalan with autologous bone marrow transplantation for multiple myeloma. Blood 67: 1298-1301, 1986.

7. Attal M, Huguet F, Schlaifer D, Payen C, Laroche M, Foumie B, Mazieres B, Pris J and Laurent G: Intensive combined therapy for previously untreated aggressive myeloma. Blood 79: 11301136, 1992.

8. Child J, Morgan G, Davies F, et al: High-dose chemotherapy with hematopoietic stem-cell rescue for multiple myeloma. N Engl J Med 348: 1875-1883, 2003.

9. Barlogie B, Shaughnessy J, Tricot G, Jacobson J, Zangari M, Anaissie E, Walker R and Crowley J: Treatment of multiple myeloma. Blood 103: 20-32, 2004.

10. Tricot G, Gazitt Y, Leemhuis T, Jagannath S, Desikan KR, Siegel D, Fassas A, Tindel S, Nelson J, Juttner C, Tsukamoto A, Hallagan J, Atkinson K, Hoffman R and Barlogie B: Collection, engraftment kinetics and tumor contamination of highly purified hematopoietic progenitor cells to support high dose therapy in multiple myeloma. Blood 91: 4489-4495, 1998.

11. Stewart AK, Vescio R, Schiller G, Ballester O, Noga S, Rugo H, Freytes C, Stadtmauer E, Tarantolo S, Sahebi F, Stiff P, Meharchard J, Schlossman R, Brown R, Tully H, Benyunes M, Jacobs C, Berenson R, White M, DiPersio J, Anderson KC and Berenson J: Purging of autologous peripheral-blood stem cells using CD34 selection does not improve overall or progressionfree survival after high-dose chemotherapy for multiple myeloma: results of a multicenter randomized controlled trial. J Clin Oncol 19: 3771-3779, 2001.

12. Singhal S, Mehta J, Desikan R, et al: Antitumor activity of thalidomide in refractory multiple myeloma. N Engl J Med 341: 1565-1571, 1999.

13. Barlogie B, Tricot $G$ and Anaissie E: Thalidomide in the management of multiple myeloma. Semin Oncol 28: 577-582, 2002.

14. Kumar S, Gertz MA, Dispenzieri A, et al: Response rate, durability of response, and survival after thalidomide therapy for relapsed multiple myeloma. Mayo Clin Proc 78: 34-39, 2003.

15. Richardson PG, Schlossman RL, Weller E, et al: Immunomodulatory drug CC-5013 overcomes drug resistance and is well tolerated in patients with relapsed multiple myeloma. Blood 100: 3063-3067, 2002.

16. Richardson PG, Hideshima T, Mitsiades C and Anderson K: Proteasome inhibition in hematologic malignancies. Ann Med 36: 304-314, 2004.

17. Hertel LW, Boder GB, Kroin JS, Rinzel SM, Poore GA, Todd GC and Grindey GB: Evaluation of the antitumor activity of gemcitabine (2',2'-difluoro-2'-deoxycytidine). Cancer Res 50: 4417-4422, 1990.

18. Waud WR, Gilbert KS, Grindey GB and Worzalla JF: Lack of in vivo crossresistance with gemcitabine against drug-resistant murine P388 leukemias. Cancer Chemother Pharmacol 38: $178-180,1996$.

19. Heinemann V, Xu YZ, Chubb S, Sen A, Hertel LW, Grindey GB and Plunkett W: Cellular elimination of $2^{\prime}, 2^{\prime}$-difluorodeoxycytidine $5^{\prime}$-triphosphate: a mechanism of self potentiation. Cancer Res 52: 533-539, 1992.

20. Ruiz von Haperen VWT, Veerman G, Boven E, Noordhuis P, Vermorken JB and Peters GJ: Schedule dependence of sensitivity to 2',2'-difluorodeoxycytidine (gemcitabine) in relation to accumulation and retention of its triphosphate in solide tumour cell lines and solid tumours. Biochem Pharmacol 48: 1327-1339, 1994.

21. Heinemann V, Hertel L W, Grindey GB and Plunkett W: Comparison of the cellular pharmacokinetics and toxicity of 2',2'-difluorodeoxyctidine and I-beta- D-arabinofuranosyl cytosine. Cancer Res 48: 4024-4031, 1988.

22. O'Rourke TJ, Brown TD, Havlin K, Kuhn JG, Craig JB, Burris HA, Satterlee WG, Tarassoff PG and Von Hoff DD: Phase I clinical trial of gemcitabine given as an intravenous bolus on 5 consecutive days. Eur J Cancer 30A: 417-418, 1994.

23. Poplin EA, Corbett T, Flaherty L, Tarasoff P, Redman BG, Valdivieso M and Baker L: Difluorodeoxycytidine (dFdC)gemcitabine: a phase I study. Invest New Drugs 10: 165-170, 1992.

24. Abbruzzese JL, Grunewald R, Weeks EA, Gravel D, Adams T, Nowak B, Mineishi S, Tarassoff P, Satterlee W, Raber MN and Plunkett W: A phase I clinical, plasma and cellular pharmacology study of gemcitabine. J Clin Oncol 9: 491-498, 1991.
25. Vermorken JB, Guastalla JP, Hatty SR, Seitz DE, Tanis B, McDaniels C and Clavel MD: Phase I study of gemcitabine using a once every 2 weeks schedule. Br J Cancer 76: 1489-1493, 1997.

26. Brand $\mathrm{R}$, Capadano $\mathrm{M}$ and Tempero $\mathrm{M}$ : A phase I trial of weekly gemcitabine administered as a prolonged infusion in patients with pancreatic cancer and other solid tumors. Invest New Drugs 15: 331-341, 1997.

27. Rowinsky EK, Cazenave LA and Donehower RC: Taxol: a novel investigational antimicrotubule agent. J Natl Cancer Inst 82: 1247-1259, 1990.

28. Rothenberg ML: Taxol, Taxotere and other new taxanes. Curr Opin Invest Drugs 2: 1269-1277, 1993.

29. Rowinsky EK and Donehower RC: Paclitaxel (taxol). N Engl J Med 332: 1004-1014, 1995.

30. Roth BJ, Dreicer R, Einhorn LH, Neuberg D, et al: Significant activity of paclitaxel in advanced transitional-cell carcinoma of the urothelium: a phase II trial of the Eastern Cooperative Oncology Group. J Clin Oncol 12: 2264-2270, 1994.

31. Murphy WK, Fossella FV, Winn RJ, Shin DM, Hynes HE, Gross HM, Davilla E, Leimert J, Dhingra H, Raber MN, et al: Phase II study of taxol in patients with untreated advanced nonsmall-cell lung cancer. J Natl Cancer Inst 85: 384-388, 1993.

32. Caldas C and McGuire WP III: Paclitaxel (Taxol) therapy in ovarian carcinoma. Semin Oncol 4 (suppl 3): 50-55, 1993.

33. Forastiere AA, Neuberg D, Taylor SG IV, DeConti R and Adams G: Phase II evaluation of Taxol in advanced head and neck cancer: an Eastern Cooperative Oncology group trial. J Natl Cancer Inst Monogr 15: 181-184, 1993.

34. Gazitt Y, Rothenberg ML, Hilsenbeck SL, Fey V, Thomas C and Montgomery W: Bcl-2 overexpression is associated with resistance to paclitaxel but not gemcitabine in multiple myeloma cell lines. Int J Oncol 13: 839-848, 1998.

35. Tolcher AW: Paclitaxel couplets with cyclophosphamide or cisplatin in metastatic breast cancer. Semin Oncol 23 (suppl 1): 37-43, 1996.

36. Rothenberg ML, Sharma A, Weiss GR, Villalona-Calero MA, Eckardt JR, Aylesworth C, Kraynak MA, Rinaldi DA, Rodriguez GI, Burris HA III, Eckhardt SG, Stephens CD, Forral K, Nicol SJ and Von Hoff DD: Phase I trial of paclitaxel and gemcitabine administered every 2 -weeks in patients with refractory solid tumors. Ann Oncol 9: 733-738, 1998.

37. Guchelaar H-J, Richel DJ and van Knapen A: Clinical, toxicological, and pharmacological aspects of gemcitabine. Cancer Treat Rev 22: 15-31, 1996.

38. Fleming TR: One sample multiple testing procedure for phase II clinical trial. Biometrics 38: 143-151, 1982.

39. Richardson P, Barlogie B, Berenson J, Singhal S, Jagannath S, Irwin D, et al: A phase 2 study of bortezomib in relapsed, refractory myeloma. N Engl J Med 348: 2609-2617, 2002.

40. Mitsiades N, Mitsiades C, Poulaki V, Chauhan D, Fanourakis G, $\mathrm{Gu}$ X, et al: Molecular sequelae of proteasome inhibition in human multiple myeloma cells. Proc Natl Acad Sci USA 99: 14374-14379, 2002.

41. Blade J, Samson D, Reece D, Apperley J, Bjorkstrand B, Gahrton $\mathrm{G}$, et al: Criteria for evaluating disease response and progression in patients with multiple myeloma treated by highdose therapy and haemopoietic stem cell transplantation. Br J Haematol 102: 1115-1123, 1998.

42. Zangari M, Siegel E, Barlogie B, Anaissie E, Saghafifar F, Fassas A, Morris C, Fink L and Tricot G: Thrombogenic activity of doxorubicin in myeloma patients receiving thalidomide: implications for therapy. Blood 100: 1168-1171, 2002.

43. Weber D, Rankin K, Gavino M, Delasalle K and Alexanian R: Thalidomide alone or with dexamethasone for previously untreated multiple myeloma. J Clin Oncol 21: 16-19, 2003.

44. Zangari M, Tricot G, Zeldis J, Eddlemon P, Saghafifar F and Barlogie B: Results of phase I study of CC-5013 for the treatment of multiple myeloma (MM) patients who relapse after high dose chemotherapy (HDCT). Blood 98: 775a, 2001.

45. Richardson PG, Sonneveld P, Schuster MW, et al: Assessment of proteasome inhibition for extending remissions (APEX) investigators. Bortezomib or high-dose dexamethasone for relapsed multiple myeloma. N Engl J Med 352: 2487-2498, 2005.

46. Kamat AM, Karashima T, Davis DW, Lashinger L, Bar-Eli M, Millikan R, Shen Y, Dinney CP and McConkey DJ: The proteasome inhibitor bortezomib synergizes with gemcitabine to block the growth of human 253JB-V bladder tumors in vivo. Molecular Cancer Therapeutics 3: 279-290, 2004. 